\title{
Differential risk of viral infections in children undergoing complex anticancer therapy or hematopoietic stem cell transplantation
}

\author{
Corresponding author: \\ Jan Styczyński, Nicolaus Copernicus \\ University, Collegium Medicum, \\ Department of Pediatric Hematology \\ and Oncology, \\ M Skłodowskiej-Curie St. 9 \\ 85-094 Bydgoszcz, Poland. \\ tel: +48525854860 \\ e-mail: jstyczynski@cm.umk.pl
}

\begin{abstract}
Background: Infections constitute a major problem for patients during oncological treatment or undergoing hematopoietic stem cell transplantation (HCT).

Objective: The aim of the study was to analyze the epidemiology of viral infections in children during anticancer therapy (PHO, pediatric haematology and oncology) or after HCT over a period of consecutive 6 years in a single-centre study.

Patients and methods: During this period, a total number of $182 \mathrm{HCTs}$ were performed, and 306 children were newly diagnosed for malignancy. Incidence, hazard risk and outcome of infections were analyzed. Results: The cumulative incidence of viral infections was $61.7 \%$ in allo-HCT, $8.5 \%$ in $\mathrm{PHO}$, and $4.1 \%$ in auto-HCT patients. The overall risk of viral infection in HCT patients was 17.3-fold higher $(p<0.0001)$ than in $\mathrm{PHO}$ patients. The risk was 30-fold higher for $\mathrm{CMV}$ and 63-fold higher for $\mathrm{EBV}$, while the risk was comparable for influenza and adenovirus infection. Infections with polyoma BKV occurred only in HCT patients after allo-HCT. Factors contributing to increased risk of viral infections in allo-HCT patients both in uni- and multivariate analysis were: male sex, diagnosis of acute leukemia, alternative donor, CMV positive serostatus in recipient and/or donor, acute and chronic GVHD. All patients except two allo-HCT children survived viral infections. The cause of death were influenza and EBV-PTLD.

Conclusions: The risk of viral infections in allo-HCT patients is much higher than in auto-HSCT and PHO patients, while the outcome of infections was better in the PHO and auto-HCT setting

Key words: viral infections, malignant diseases, pediatric haematology and oncology, hematopoietic stem

cell transplantation, children
\end{abstract}

Med Res J 2018; 3 (3): 127-133
Volume 3 Nesearch Journal 2018; 10.5603/MRJ.2018.20021 Copyright $\odot 2018$ Via Medica ISSN 2451-2591

\section{Introduction}

Infections constitute a major problem for patients during oncological treatment or undergoing hematopoietic stem cell transplantation (HCT). Children with malignancies ( $\mathrm{PHO}$, pediatric hemato-oncology/oncology diseases) and after HCT are at risk of viral infections due to an impairment of the immune system. Factors predisposing a child to infection include alterations in the body's natural barriers, the presence of central venous catheters, intensive chemotherapy, alterations in the innate immune system and acquired immunity. Due to clinical reasons, in HCT setting viral infections are divided as latent (herpesviruses, polyoma BKV) and sporadic (adenovirus - ADV, rotavirus - RV, influenza - FLU and others).
In immunocompromised patients, viruses cause double negative: direct and indirect effects. The direct effect of the virus depends on its lytic infection, such as pneumonia, gastro-intestinal disease, retinitis, hepatitis and myelosuppression. Indirect effects of the virus include immunosuppression and facilitating of fungal and bacterial infections. In HCT patients, viral infections can also cause graft failure, graft rejection and GVHD (graft-versus-host disease). These effects are most prominent for $\mathrm{CMV}$ infection, however, can occur also after other viral infections.

In a single-centre study in the USA, infections occur in $82 \%$ of children after allogeneic HCT (allo-HCT) [1], and in $49 \%$ of children with acute leukaemia [2]. Viral infections occurred in $11 \%$ of children undergoing au- 
to-HCT [2], and after allo-HCT in $20 \%$ of children before day +30 , in $18 \%$ between days +30 until +100 and in $19 \%$ after day +100 [1]. Among all allo-HCT infectious deaths, $24 \%$ were caused by viruses [1], while deaths due to infections were rare after auto-HCT [2]. Infections with cytomegalovirus (CMV) was one of the major risk factors for death after HCT [3-4].

The objective of the study was to analyze the incidence and outcome of viral infections in children during anticancer therapy ( $\mathrm{PHO}$, pediatric hematology and oncology) or after HCT over a period of consecutive 6 years in a single-center study.

\section{Patients and methods}

Patients. All consecutive patients undergoing treatment for malignant diseases (PHO patients) or undergoing HCT, treated in the Department of Pediatric Hematology and Oncology and in the Department of Pediatric Surgery were included in this study. Data on viral infections diagnosed between 1.01.2012-31.12.2017 were reported and analyzed. In 2012-2013 the study was retrospective and from 2014 prospective.

Diagnosis of viral infections. Viral infections were classified as episodic (diagnosed on the basis of the clinical picture, and supplemented with appropriate tests), or latent ones (requiring monitoring at the molecular level) [5-7]. The following viruses were detected by PCR analysis: adenovirus (ADV), polyoma BKV, cytomegalovirus (CMV), Epstein-Barr Virus (EBV), human herpesvirus 6 (HHV-6) and influenza (FLU). The preemptive approach was introduced for infections with two latent viruses: CMV and EBV, only in allo-HCT patients, according to ECIL recommendations [6-7].

Anti-infective prophylaxis. Uniform, standard anti-infective prophylaxis has been applied for patients in neutropenia and those undergoing HCT [6-9]. Empirical, preemptive or targeted anti-infectious therapy was performed with various antibacterial, antiviral and antifungal agents according to commonly accepted strategies [6-11]. Additionally, environmental prophylaxis was applied in all centres.

Management of viral infections. The preemptive approach was introduced only for infections with two latent viruses: CMV and EBV, and only in allo-HCT patients, according to European ECIL recommendations. Since there are no existing recommendations to perform any other preemptive strategy for other viruses, and in other settings, especially in non-transplanted patients - in most cases, the diagnosis of viral infection was made on the basis of clinically-driven testing.

Statistical analysis. The infectious event was defined as the diagnosis of a first specific infectious disorder. Categorical variables were compared with the chi-square test, non-categorical variables were compared with the Mann-Whitney $U$ test. Hazard risk (HR) and confidence intervals $(\mathrm{Cl})$ were calculated for the difference in the occurrence of infections in patients. Cumulative incidences of viral infections were calculated using competing risk analysis [12], starting from the day of transplant in the HCT setting, or the day of cancer diagnosis in the PHO setting, to the day of the first infection. Death was considered as the competing event. The Kaplan-Meier method was used to determine infection-related mortality and overall survival (OS) [13].

Multivariate models for the development of viral infections were calculated using the Cox model. Variables analyzed in HCT patients included age ( $\leq 10$ years, > 10 years), sex (female, male), donor source (MSD, MUD/MMUD), disease (acute leukemia, other), conditioning intensity (myeloablative, other), donor/recipient CMV serostatus (negative/negative, any positive), acute GVHD as a time-dependent covariate occurring before infection onset (grade 0/1, grade $2-4$ ), and chronic GVHD as a time-dependent covariate occurring before infection onset (no, yes). Use of ATG (anti-thymocyte globulin) was the variable dependent on alternative donor, as it was used almost exclusively in MUD/MMUD transplants. Variables analyzed in $\mathrm{PHO}$ patients included age ( $\leq 10$ years, $>10$ years), sex (female, male) and disease (acute leukaemia, other). The stepwise selection procedure was used to select significant covariates. All reported $p$-values are two-sided; $p<0.05$ was considered as statistically significant.

\section{Results \\ Demographics}

Over an analyzed period of 72 consecutive months, a total number of $306 \mathrm{PHO}$ patients were newly diagnosed for malignancy, including 81 with acute lymphoblastic leukemia (ALL), 10 with acute myeloblastic leukemia (AML), 30 with non-Hodgkin lymphoma (NHL), 32 with Hodgkin disease (HD), 48 with central nervous system tumors (CNS), 13 with neuroblastoma (NBL), 15 with Wilms tumor (WT), 12 with Ewing sarcoma (ES) and 51 with other solid tumors (ST). During this period, a total number of 182 HCTs were performed including 133 allo-HCTs and 49 auto-HCTs. Children were transplanted due to ALL $(n=54), \operatorname{AML}(n=3), N H L / H D(n=17)$, bone marrow failure syndromes (BMF, $n=19)$, primary immunodeficiencies (PID, $n=11$ ), neuroblastoma (NBL, $n=66$ ), Ewing sarcoma $(n=18)$ or other diseases $(n=69)$.

\section{Incidence of infections}

The cumulative incidence of viral infections between 2012-2017 in PHO patients was 8.5\% $(95 \% \mathrm{Cl}$ $=5.4-11.6)$, while in auto-HCT patients it was $4.1 \%$ 


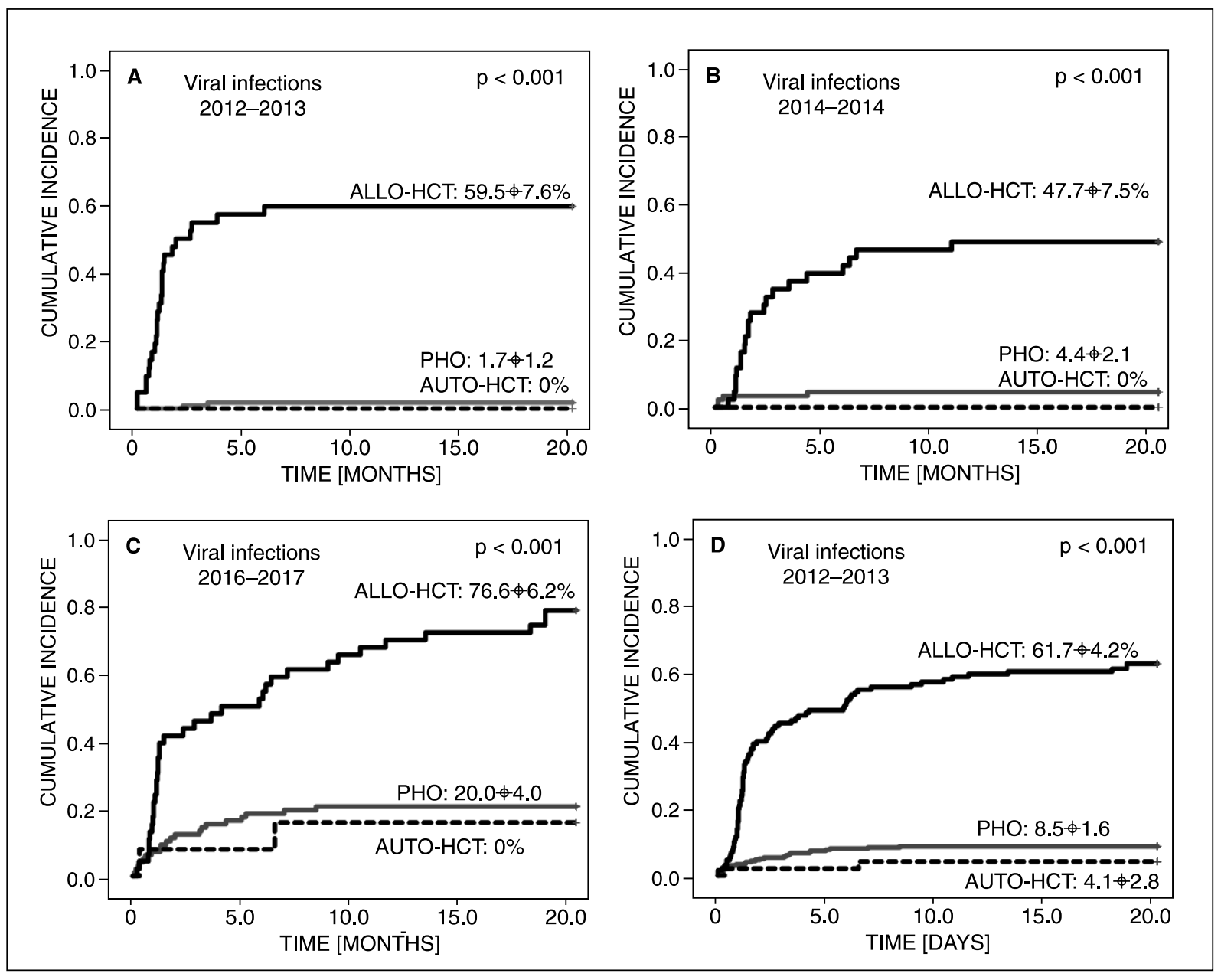

Figure 1. Cumulative incidence of viral in PHO and HCT settings with respect to time periods: (A) 2012-2013; (B) 2014-2015; (C) 2016-2017; (D) 2012-2017 together

$(95 \% \mathrm{Cl}=1.5-9.6)$ and in allo-HCT, it was $61.7 \%(95 \%$ $\mathrm{Cl}=53.4-69.9)$. Respective values for subsequent two-years periods are presented in Figure 1.

The risk of viral infection in HCT patients was 17.3-fold higher $(p<0.0001)$ than in $\mathrm{PHO}$ patients (Table 1). The risk was 30 -fold higher for CMV $(95 \%$ $\mathrm{Cl}=10-86 ; \mathrm{p}<0.0001$ ) and 63-fold higher for EBV $(95 \% \mathrm{Cl}=8-477 ; \mathrm{p}<0.0001)$, while the risk was comparable for adenovirus infection ( $\mathrm{HR}=0.9 ; 95 \%$ $\mathrm{Cl}=0.4-2.4 ; \mathrm{p}=0.86)$, and influenza $(\mathrm{HR}=2.3$; $95 \% \mathrm{Cl}=0.3-16 ; \mathrm{p}=0.39)$. Infections with BKV occurred only in HCT patients after allo-HCT. In PHO patients, infections with EBV and HHV6 occurred only at diagnosis, thus should be treated as related to primary malignancy. Multiple viral infections occurred in 4/133 (3.0\%) allo-HSCT patients.

With respect to the type of transplant, the cumulative incidence of viral infections was much higher after allo-HCT than after auto-HCT: $61.7 \%$ vs $4.1 \%(\mathrm{HR}=37.7$, $95 \% \mathrm{Cl}=8.8-162 ; \mathrm{p}<0.0001)$.
Most of the viral infections occurred within the first three months, both after allo-HCT and in PHO patients after diagnosis of the malignancy. The median time to first viral infection was the same after HCT and in the $\mathrm{PHO}$ patients after diagnosis of malignancy: 36 days vs 36 days, $p=0.99$. Due to sporadic infections after auto-HCT, the respective comparison was not done.

The incidence of viral infections in allo-HCT patients has increased in the most recent period (Figure 2A). The most frequent viral infections among allo-HCT patients were: CMV, EBV, BKV and ADV (Figure 2B). The incidence of $A D V$ infections was comparable in these three settings (Figure $2 \mathrm{C}$ ), however, most of ADV infections were detected over a recent period (Figure 2D).

\section{Risk factors of infections in allo-HCT patients}

Factors contributing to increased risk of viral infections both in uni- and multivariate analysis were: male sex, diagnosis of acute leukaemia, alternative 
Table 1. Hazard risk of infections after HCT compared to PHO patients with respect to time periods

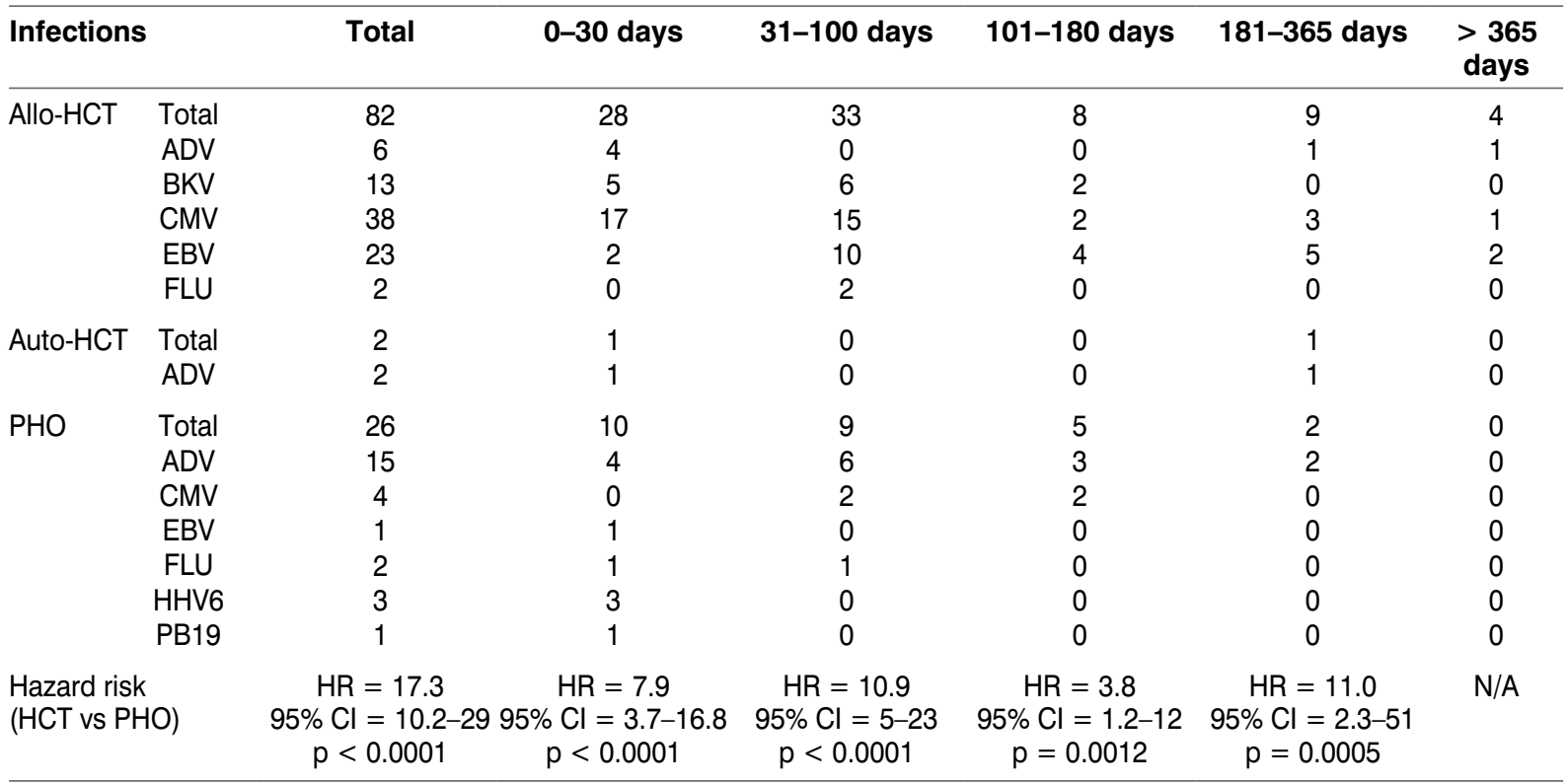

$\mathrm{HR}$ - hazard risk; $\mathrm{Cl}$ - confidence interval; $\mathrm{p}$ - p-value; N/A - not applicable



Figure 2. Cumulative incidence of viral in $\mathrm{PHO}$ and HSCT settings with respect to time periods: $(A)$ in allo-HCT; (B) for CMV, EBV, BKV and ADV infections; (C) for ADV infections in PHO and HCT patients between 2012-2017; (D) for ADV infections in PHO and HCT patients between 2016-2017. 
Table 2. Risk factor analysis for viral infections in allo-HCT patients

\begin{tabular}{|c|c|c|c|c|c|}
\hline \multirow[t]{2}{*}{ Variable } & \multirow[t]{2}{*}{ Characteristics } & \multicolumn{2}{|c|}{ Univariate analysis } & \multicolumn{2}{|c|}{ Multivariate analysis } \\
\hline & & Frequency & p-value & $\begin{array}{l}\text { RR } \\
(95 \% \mathrm{Cl})\end{array}$ & p-value \\
\hline Sex & $\begin{array}{l}\text { Female } \\
\text { Male }\end{array}$ & $\begin{array}{l}25 / 51(49.0 \%) \\
57 / 82(69.5 \%)\end{array}$ & 0.018 & $\begin{array}{l}1 \\
2.3(1.1-4.9)\end{array}$ & 0.029 \\
\hline Age & $\begin{array}{l}<10 \text { years } \\
>10 \text { years }\end{array}$ & $\begin{array}{l}40 / 67(59.7 \%) \\
42 / 66(63.6 \%)\end{array}$ & 0.640 & $\begin{array}{l}1 \\
1.1(0.5-2.4)\end{array}$ & 0.770 \\
\hline Disease & $\begin{array}{l}\text { Other } \\
\text { Acute leukemia }\end{array}$ & $\begin{array}{l}8 / 46(17.4 \%) \\
74 / 87(85.1 \%)\end{array}$ & $<0.0001$ & $\begin{array}{l}1 \\
27(10-70)\end{array}$ & $<0.0001$ \\
\hline Donor & $\begin{array}{l}\text { MFD } \\
\text { other }\end{array}$ & $\begin{array}{l}11 / 33(33.3 \%) \\
71 / 100(71.0 \%)\end{array}$ & $<0.0001$ & $\begin{array}{l}1 \\
4.8(2.1-11)\end{array}$ & 0.0002 \\
\hline Conditioning & $\begin{array}{l}\text { Myeloablative } \\
\text { Other }\end{array}$ & $\begin{array}{l}54 / 79(68.4 \%) \\
28 / 54(51.9 \%)\end{array}$ & 0.054 & $\begin{array}{l}1 \\
0.5(0.2-1.1)\end{array}$ & 0.081 \\
\hline $\begin{array}{l}\text { CMV serostatus } \\
\text { (donor/recipient) }\end{array}$ & $\begin{array}{l}\text { Both negative } \\
\text { Other }\end{array}$ & $\begin{array}{l}1 / 8(12.5 \%) \\
81 / 125(64.8 \%)\end{array}$ & 0.003 & $\begin{array}{l}1 \\
12(1.5-108)\end{array}$ & 0.010 \\
\hline Acute GVHD & $\begin{array}{l}\text { No } \\
\text { Yes }\end{array}$ & $\begin{array}{l}57 / 102(55.9 \%) \\
25 / 31(80.6 \%)\end{array}$ & 0.013 & $\begin{array}{l}1 \\
3.3(1.2-8.7)\end{array}$ & 0.023 \\
\hline Chronic GVHD & $\begin{array}{l}\text { No } \\
\text { Yes }\end{array}$ & $\begin{array}{l}64 / 113(56.6 \%) \\
18 / 20(90.0 \%)\end{array}$ & 0.004 & $\begin{array}{l}1 \\
6.9(1.5-31)\end{array}$ & 0.009 \\
\hline
\end{tabular}

GVHD - graft-versus-host-disease; MFD - matched family donor; RR - relative risk

Table 3. Viral infections in allo-HCT patients

\begin{tabular}{lccccc}
\hline Infection & $\mathbf{N}$ & $\begin{array}{c}\text { Age [years] } \\
\text { (median, range) }\end{array}$ & $\begin{array}{c}\text { Time to infection [months] } \\
\text { (median, range) }\end{array}$ & Treatment & $\begin{array}{c}\text { Survival } \\
\text { rate }\end{array}$ \\
\hline CMV & 38 & $10.7(2.7-18)$ & $1.1(0.7-13.2)$ & Ganciclovir, foscarnet, cidofovir & $38 / 38$ \\
EBV & 23 & $9.2(2.4-18)$ & $2(0.8-13.0)$ & Rituximab & $22 / 23$ \\
BKV & 13 & $12.7(7.1-18)$ & $1.3(0.8-4.1)$ & Cidofovir & $13 / 13$ \\
ADV & 6 & $7.4(1.9-12.1)$ & $0.9(0.2-13.7)$ & Cidofovir or symptomatic & $6 / 6$ \\
FLU & 2 & $9.3(3.6-14.9)$ & $1.7(1.4-2)$ & Oseltamivir & $1 / 2$ \\
\hline
\end{tabular}

donor (other than matched family donor), CMV positive serostatus in recipient and/or donor, acute and chronic GVHD. Table 2 provides the results of a multivariate analysis comparing infections among the different risk factors (Table 2). Viral infections were also less likely after non-myeloablative or reduced-intensity conditioning however it did not reach statistical significance.

\section{Survival after viral infections}

All PHO patients and all but two HCT patients survived viral infections. Two patients after HCT clearly died due to infectious complications: after influenza infection, and after EBV-PTLD. Nevertheless, several other patients with $\mathrm{CMV}$ reactivation proceeded to invasive fungal diseases and deceased. The treatment and outcome of viral infections are shown in Table 3.

\section{Discussion}

In this paper, we report the results of a single-centre study of the risk and outcome of viral infections in pediatric HCT and PHO patients. All patients in respective groups were treated with the same therapeutic protocols, using comparable principles of supportive therapy.

The two main messages came from this study: first - that the risk of viral infections after allo-HCT is very high, especially for patients with acute leukaemia; and the second - that the outcome of viral infections in $\mathrm{PHO}$ and HCT pediatric patients is good. On the other hand, the risk of viral infections after auto-HCT is the same as it is during conventional chemotherapy for pediatric malignancies.

The four viruses which show the highest incidence in allo-HCT patients are CMV, BKV, EBV and ADV. In comparison to results obtained in the report of a 2-year nationwide study of infections in pediatric 
hemato-oncology and stem cell transplant centres [14], it should be mentioned that the profile of viral infections in allo-HCT setting is comparable over calendar time and similar with respect to other pediatric HCT centres [1].

The three viruses with the highest incidence in allo-HCT patients belong to latent infections: CMV, BKV and EBV. Infections with these viruses are related to the impairment of recipient immune system, resulting mainly in a reactivation of latent infections in allo-HCT patients. Comparison of the incidence of viral infections in $\mathrm{PHO}$, auto-HCT, and allo-HCT patients shows that it refers to the substantial differences in immunological impairment after allo-HCT. With the very high worldwide prevalence of CMV and EBV infection, these two viruses still remain major threats aggravating morbidity and mortality after allo-HCT [6,7,15-17].

It is currently estimated that the median rate of CMV reactivation is about $37 \%$ after allogeneic transplant and $12 \%$ after autologous transplant, while $5 \%$ in patients with nontransplant haematological malignancies, 30\% in solid organ transplant recipients, and $21 \%$ in patients with primary immunodeficiencies [18]. The summary of the published data shows that CMV disease occurred in $13.9 \%$ of CMV-seropositive recipients and in $1.7 \%$ of CMV-seronegative recipients of allo-HCT [18].

The median reported the incidence of EBV reactivation after allo-HCT is $29.4 \%$, with the range between $0.1-63 \%$ and is largely dependent on the type of transplant, EBV assay sensitivity, defined level of EBV-DNA-emia, use of systematic screening, and its timing [19]. The overall incidence of EBV-related PTLD (post-transplant lymphoproliferative disorder) after allo-HCT is estimated to be $3.2 \%[16,19]$.

Infection with polyoma BKV occurs in $8-25 \%$ of pediatric and $7-54 \%$ of adult recipients undergoing allo-HCT. Age of the HCT recipient $>7$ years is regarded as a risk factor for BKV reactivation [20]. CMV or human herpesvirus 6 (HHV6) viremia facilitates BKV hemorrhagic cystitis [21].

The reported frequency of invasive ADV infections in the allo-HCT setting is considerably higher in pediatric patients (6-42\%) than in adults (3-15\%), but the clinical manifestations can be equally severe [22-23]. With these data, probably the incidence of community-acquired respiratory viral (CARV) infections, including $A D V$, is underestimated in our centre, as just with the improvement diagnostics towards ADV over last two years, the incidence of ADV infections relatively increased.

Despite much progress in understanding the pathogenesis, epidemiology and risk factors of CMV, EBV, BKV, and ADV, infections with these viruses or their reactivations still represent a major unmet clinical need with limited prophylactic and therapeutic options. To overcome this deficiency novel antiviral treatment approaches supported by proper clinical trials are necessary.

Author contributions: JS had primary responsibility for study design. PG and JS performed the analysis and wrote the manuscript. MD, PG and KC collected data. All authors contributed to data interpretation and critical revision of the manuscript.

Disclosure: All Authors declare no conflict of interest.

Acknowledgements: Zakład Diagnostyki

Laboratoryjnej (Poznań), for performing viral tests.

\section{References}

1. Srinivasan A, Wang C, Srivastava DK, et al. Timeline, epidemiology, and risk factors for bacterial, fungal, and viral infections in children and adolescents after allogeneic hematopoietic stem cell transplantation. Biol Blood Marrow Transplant. 2013; 19(1): 94-101, doi: 10.1016/j. bbmt.2012.08.012, indexed in Pubmed: 22922523.

2. Srinivasan A, McLaughlin L, Wang $C$, et al. Early infections after autologous hematopoietic stem cell transplantation in children and adolescents: the St. Jude experience. Transpl Infect Dis. 2014; 16(1): 90-97, doi: 10.1111/tid.12165, indexed in Pubmed: 24256514.

3. Bjorklund A, Aschan J, Labopin M, et al. Risk factors for fatal infectious complications developing late after allogeneic stem cell transplantation. Bone Marrow Transplant. 2007; 40(11): 1055-1062, doi: 10.1038/sj.bmt.1705856, indexed in Pubmed: 17891187.

4. Martino R, Kerguelen A, Valcárcel D, et al. Reduction of infection-related mortality after allogeneic PBSCT from HLA-identical siblings: longitudinal analysis from 1994 to 2008 at a single institution. Bone Marrow Transplant. 2011; 46(5): 690-701, doi: 10.1038/bmt.2010.177, indexed in Pubmed: 20818448

5. Marr KA. Delayed opportunistic infections in hematopoietic stem cell transplantation patients: a surmountable challenge. Hematology Am Soc Hematol Educ Program. 2012; 2012: 265-270, doi: 10.1182/asheducation-2012.1.265, indexed in Pubmed: 23233590.

6. Ljungman $\mathrm{P}$, de la Camara R, Cordonnier $\mathrm{C}$, et al. European Conference on Infections in Leukemia. Management of CMV, HHV-6, HHV-7 and Kaposi-sarcoma herpesvirus (HHV-8) infections in patients with hematological malignancies and after SCT. Bone Marrow Transplant. 2008; 42(4): 227-240, doi: 10.1038/bmt.2008.162, indexed in Pubmed: 18587440

7. Styczynski J, Reusser P, Einsele $\mathrm{H}$, et al. Second European Conference on Infections in Leukemia. Management of HSV, VZV and EBV infections in patients with hematological malignancies and after SCT: guidelines from the Second European Conference on Infections in Leukemia. Bone Marrow Transplant. 2009; 43(10): 757-770, doi: 10.1038/bmt.2008.386, indexed in Pubmed: 19043458.

8. Styczynski J, Gil L. EBMT Paediatric Diseases Working Party. Prevention of infectious complications in pediatric HSCT. Bone Marrow Transplant. 2008; 42 Suppl 2: 77-81, doi: 10.1038/bmt.2008.289, indexed in Pubmed: 18978751

9. Maertens J, Marchetti O, Herbrecht R, et al. European guidelines for antifungal management in leukemia and hematopoietic stem cell transplant recipients: summary of the ECIL 3 - 2009 Update. Bone Marrow Transplantation. 2010; 46(5): 709-718, doi: 10.1038/bmt.2010.175.

10. Averbuch D, Cordonnier C, Livermore DM, et al. ECIL4, a joint venture of EBMT, EORTC, ICHS, ESGICH/ESCMID and ELN. Targeted therapy against multi-resistant bacteria in leukemic and hematopoietic stem cell transplant recipients: guidelines of the 4th European Conference on Infections in Leukemia (ECIL-4, 2011). Haematologica. 2013; 98(12): 1836-1847, doi: 10.3324/haematol.2013.091330, indexed in Pubmed: 24323984

11. Averbuch D, Orasch C, Cordonnier C, et al. ECIL4, a joint venture of EBMT, EORTC, ICHS, ESGICH/ESCMID and ELN. European guidelines for empirical antibacterial therapy for febrile neutropenic patients in the era of growing resistance: summary of the 2011 4th European Conference on Infections in Leukemia. Haematologica. 2013; 
98(12): 1826-1835, doi: 10.3324/haematol.2013.091025, indexed in Pubmed: 24323983.

12. Gooley TA, Leisenring W, Crowley J, et al. Estimation of failure probabilities in the presence of competing risks: new representations of old estimators. Stat Med. 1999; 18(6): 695-706, indexed in Pubmed: 10204198.

13. Kaplan EL, Meier P. Nonparametric Estimation from Incomplete Observations. Journal of the American Statistical Association. 1958; 53(282): 457-481, doi: 10.1080/01621459.1958.10501452.

14. Styczynski J, Czyzewski K, Wysocki M, et al. Polish Society of Paediatric Oncology and Haematology. Increased risk of infections and infection-related mortality in children undergoing haematopoietic stem cell transplantation compared to conventional anticancer therapy: a multicentre nationwide study. Clin Microbiol Infect. 2016; 22(2): 179.e1-179.e10, doi: 10.1016/j.cmi.2015.10.017, indexed in Pubmed: 26493843.

15. Zaia J, Baden L, Boeckh MJ, et al. Center for International Blood and Marrow Transplant Research, National Marrow Donor Program, European Blood and Marrow Transplant Group, American Society of Blood and Marrow Transplantation, Canadian Blood and Marrow Transplant Group, Infectious Disease Society of America, Society for Healthcare Epidemiology of America, Association of Medical Microbiology and Infectious Diseases Canada, Centers for Disease Control and Prevention. Viral disease prevention after hematopoietic cell transplantation. Bone Marrow Transplant. 2009; 44(8): 471-482, doi: 10.1038/bmt.2009.258, indexed in Pubmed: 19861981.

16. Styczynski J, Gil L, Tridello G, et al. Infectious Diseases Working Party of the European Group for Blood and Marrow Transplantation. Response to rituximab-based therapy and risk factor analysis in Epstein Barr Virus-related lymphoproliferative disorder after hematopoietic stem cell transplant in children and adults: a study from the Infectious Diseases
Working Party of the European Group for Blood and Marrow Transplantation. Clin Infect Dis. 2013; 57(6): 794-802, doi: 10.1093/cid/cit391, indexed in Pubmed: 23771985.

17. Czyzewski K, Styczynski J, Krenska A, et al. Intrathecal therapy with rituximab in central nervous system involvement of post-transplant lymphoproliferative disorder. Leuk Lymphoma. 2013; 54(3): 503-506, doi: 10.3109/10428194.2012.718342, indexed in Pubmed: 22873830.

18. Styczynski J. Who Is the Patient at Risk of CMV Recurrence: A Review of the Current Scientific Evidence with a Focus on Hematopoietic Cell Transplantation. Infect Dis Ther. 2018; 7(1): 1-16, doi: 10.1007/s40121017-0180-z, indexed in Pubmed: 29204910.

19. Styczynski J. Managing post-transplant lymphoproliferative disorder. Expert Opinion on Orphan Drugs. 2016; 5(1): 19-35, doi: 10.1080/21678707.2017.1262256

20. Cesaro S, Dalianis T, Hanssen Rinaldo C, et al. ECIL-6 Group. ECIL guidelines for the prevention, diagnosis and treatment of $\mathrm{BK}$ polyomavirus-associated haemorrhagic cystitis in haematopoietic stem cell transplant recipients. J Antimicrob Chemother. 2018; 73(1): 12-21, doi: 10.1093/jac/dkx324, indexed in Pubmed: 29190347.

21. Han TT, Xu LP, Liu DH, et al. Cytomegalovirus is a potential risk factor for late-onset hemorrhagic cystitis following allogeneic hematopoietic stem cell transplantation. Am J Hematol. 2014; 89(1): 55-61, doi: 10.1002/ajh.23584, indexed in Pubmed: 24009106.

22. Lion T. Adenovirus infections in immunocompetent and immunocompromised patients. Clin Microbiol Rev. 2014; 27(3): 441-462, doi: 10.1128/CMR.00116-13, indexed in Pubmed: 24982316.

23. Hiwarkar P, Kosulin K, Cesaro S, et al. Management of adenovirus infection in patients after haematopoietic stem cell transplantation: State-of-the-art and real-life current approach: A position statement on behalf of the Infectious Diseases Working Party of the European Society of Blood and Marrow Transplantation. Rev Med Virol. 2018; 28(3): e1980, doi: 10.1002/rmv.1980, indexed in Pubmed: 29663594. 